\title{
Cryptococcal panniculitis in a renal transplant recipient: case report and review of literature
}

\author{
Sunil K. Kothiwala ${ }^{1}$, Mahesh Prajapat ${ }^{1}$, Chhitar Mal Kuldeep ${ }^{1}$, Arpita Jindal ${ }^{2}$
}

1. Department of Dermatology and Venereology, SMS Medical College and Attached Hospitals, Jaipur, Rajasthan India;

2. Department of Pathology, SMS Medical College and Attached Hospitals, Jaipur, Rajasthan India.

\section{Corresponding author:}

Sunil K. Kothiwala

Department of Dermatology and Venerology

SMS Medical College and Attached Hospitals

Jaipur, Rajasthan India

E-mail:

drsunilkothiwala.aiims@gmail.com

\section{Key words:}

cryptococcus, fungal infection, immunosuppression, mycophenolate mofetil, panniculitis, prednisone, tacrolimus

\section{Abstract}

Background: Cryptococcosis is a deep fungal infection caused by Cryptococcus neoformans. The infection usually involves the lungs, the central nervous system as well as the skin, the bones and the urinary tract. Immunocompromised individuals, including solid organ transplant recipients, are at higher risk for cryptococcal infections.

Main observations: We present a 40-year-old renal transplant recipient who developed a slightly painful, erythematous, indurated plaque on his thigh several years after a kidney transplant. Histopathology revealed cryptococcal panniculitis and cryptococcus neoformans subsequently grew from the tissue culture. There was no other systemic involvement.

Conclusion: The primary cutaneous form of cryptococcosis is extremely rare and early diagnosis and treatment is essential in view of possible dissemination and variable nonspecific clinical manifestations. (J Dermatol Case Rep. 2015; 9(3): 76-80)

\section{Introduction}

Cryptococosis is a systemic fungal infection caused by Cryptococcus neoformans, characterized as a species of encapsulated yeasts which, based on the capsule structure, are grouped into two varieties i.e. neoformans and gatti. Cryptococcus neoformans var gattii primarily occurs in immunocompetent hosts whereas $90 \%$ of Cryptococcus neoformans var neoformans infections occur in immunocompromised hosts and may cause significant morbidity and mortality in the host. ${ }^{1}$ Solid organ transplant is one of the major risk factors for Cryptococcus in non-HIV-infected patients. In transplant recipients, infection with cryptococcal species presents across a wide spectrum usually as meningoencephalitis and pneumonitis, with cutaneous infections appearing uncommonly. ${ }^{2}$ Cutaneous cryptococcosis can have drastically varied presentations, from papules to a more subtle cellulitis and mimic other dermatological entities. Cutaneous lesions have to be considered seriously because they may be the first clinical sign of cryptococcosis and may be an indicator of systemic dissemination. This case report highlights the uncommon and subtle presentation of cutaneous cryptococcosis in an immunocompromised patient and encourages a high index of suspicion for this potentially fatal disease in the context of immunosuppression.

\section{Case Report}

A 40-year-old man who had renal transplantation 8 years earlier presented with a 7-month history of a single erythematous thick plaque over the medial side of right thigh associated with pain and itching with no systemic symptoms. According to anamnesis the plaque gradually progressed in size and thickness over a period of 7 months. There was no history of oozing or bleeding from the lesion, fever, nausea, vomiting, arthralgia, headache or any other systemic symptoms. Eight years earlier, the patient was diagnosed to have oligospermia due to partial obstruction of seminal pathways. Following instrumentation for this purpose, the 


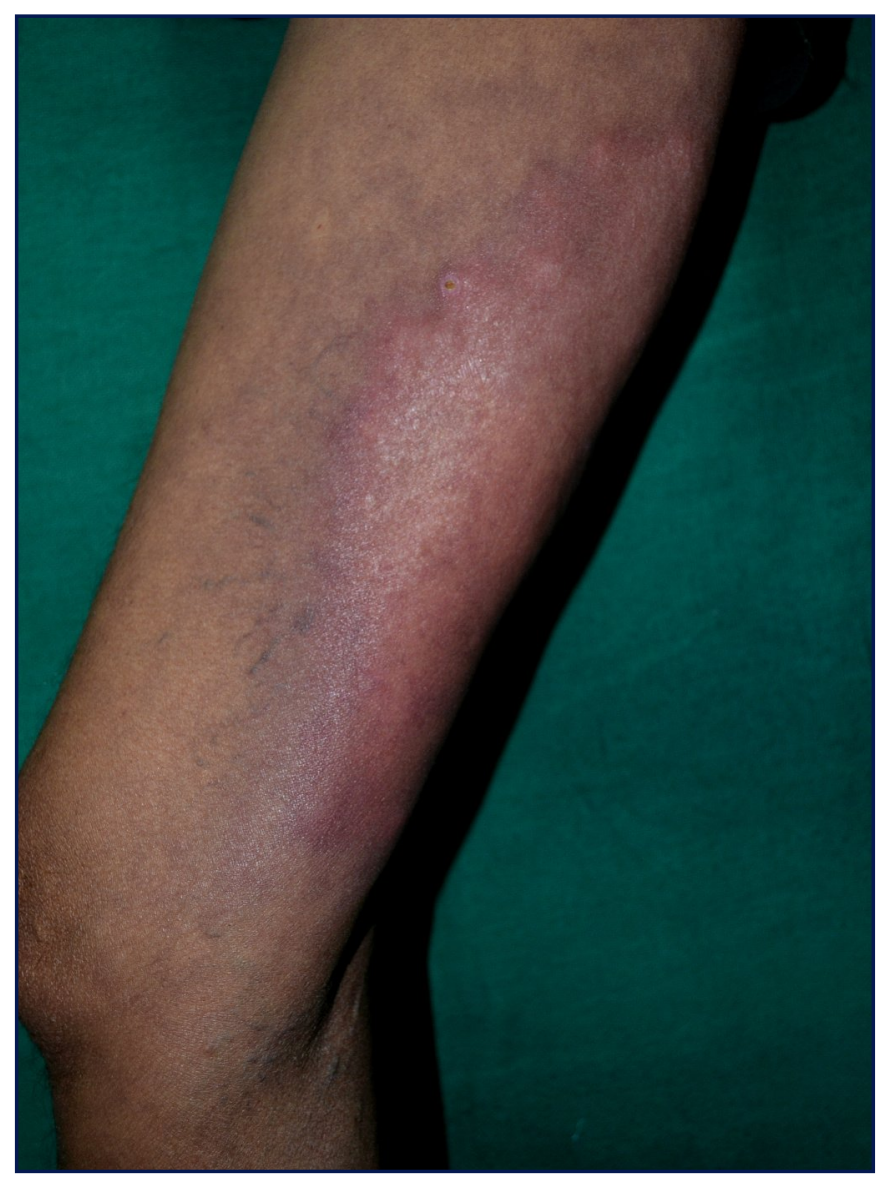

Figure 1

Single erythematous ill-defined, irregular, indurated, tender plaque with elevated margins over medial aspect of right thigh.

patient developed recurrent urinary tract infections. During the diagnostic procedures he was found to have a congenital unilateral right sided kidney. Later the patient developed renal scarring which necessitaed renal allograft transplantation. At the time of presentation the patient received tacrolimus $1.5 \mathrm{mg}$ twice daily, mycophenolate mofetil $500 \mathrm{mg}$ twice daily, and prednisolone $5 \mathrm{mg}$ once daily. Additional treatment consisted of clindipine $10 \mathrm{mg}$ and prazosin $5 \mathrm{mg}$.

Dermatological examination revealed the presence of a single erythematous ill-defined, irregular, indurated, tender plaque with elevated margins over medial aspect of right thigh extending from just beneath the gluteal fold to superior aspect of popliteal fossa of size measuring from $15 \mathrm{~cm}$ x $5 \mathrm{~cm}$ in greatest dimensions (Fig. 1). Multiple prominent capillaries were visible at periphery, both in and outside of the lesion. The veins surrounding the lesion were engorged. There was no lymphadenopathy. Skin biopsy was taken with possibility of infective panniculitis attributed to deep fungal infection and sent for histopathology and fungal culture.

Histopathology examination with heamatoxylin and eosin stain showed unremarkable epidermis, diffuse dermal granulomatous infiltrate composed of epitheloid cells, plasma cells, eosinophils, and foreign body giant cells (Fig. 2A).

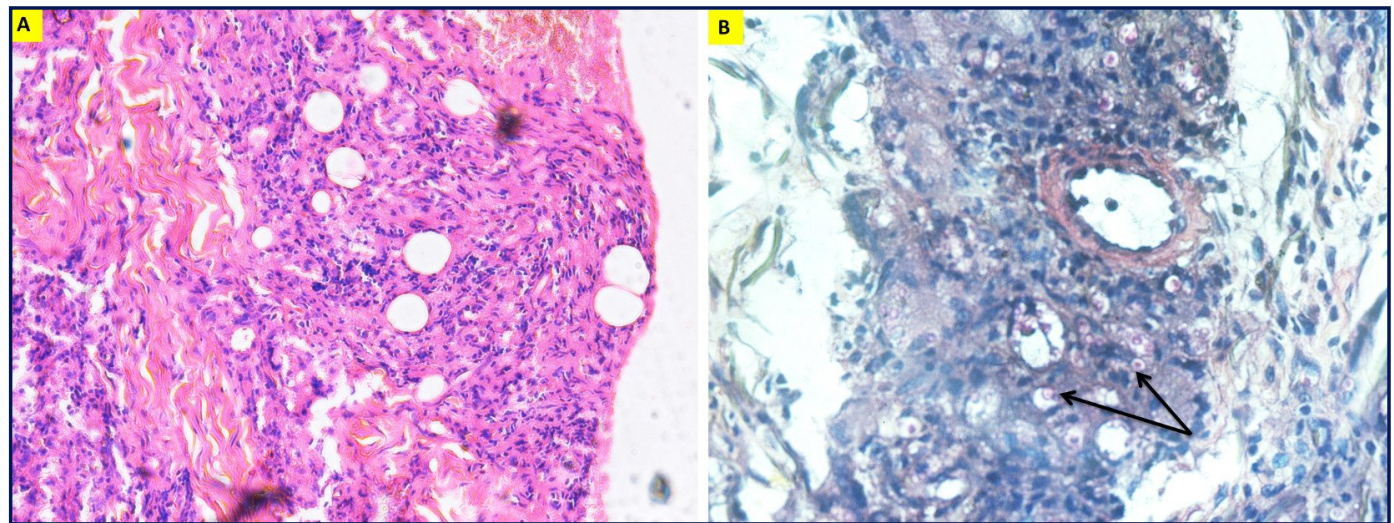

Figure 2

Histopathology showing: (A) ill-defined granulomas in the subcutaneous tissue with yeast like organism in macrophag (Haematoxylin \& Eosin, 100X) and (B) numerous encapsulated yeasts in macrophages). (Mucicarmine stain, 400X).
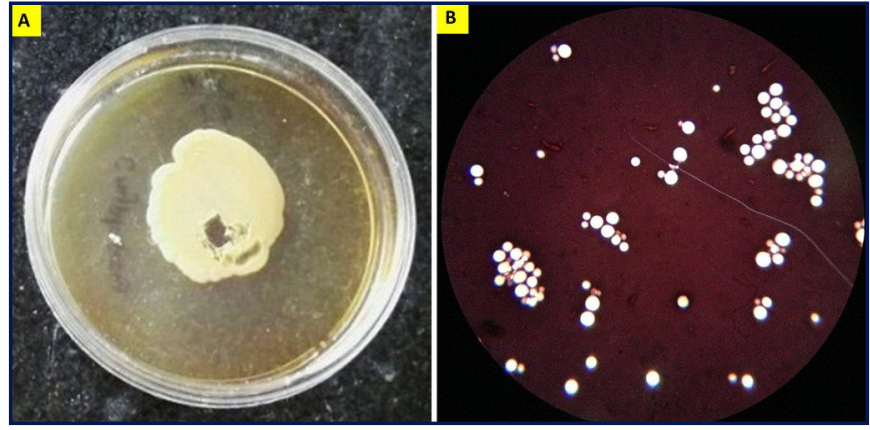

Figure 3

Tissue culture showed cream colored smooth mucoid yeast like colonies on bouraud dextrose agar (A), and India ink-safranin stain showing budding encapsulated yeasts $(B)(400 X)$
Numerous encapsulated yeast were present in macrophages and giant cells on mucicarmine stain (Fig. 2B). Tissue culture showed cream colored smooth mucoid yeast like colonies on sabouraud dextrose agar (Fig. 3A) and india ink plus safaranin staining showed encapsulated budding yeasts (Fig. 3B).

Based on clinical, Histopathological and culture findings diagnosis of cryptococcal panniculitis was made. The patient was evaluated for systemic involvement. Cerebrospinal fluid and serum were negative for antigen detection. Other investigations including urine microscopy, chest Xray were within normal limits. As patient had only cutaneous involvement without any systemic involvement, itraconazole $200 \mathrm{mg}$ twice daily was introduced. Monthly followup allowed to evaluate gradual therapeutic response. 


\section{Discussion}

In 1894, Busse first described the cryptococcus species that is an encapsulated yeasts measuring 4-20 $\mu \mathrm{m}$. Based on the capsule structure, they were grouped into two varieties that included five serotypes. C. neoformans var. neoformans including serotypes A, D and AD, and C. neoformans var. gatti contained strains with serotypes B and C. Based on DNA genotyping methods, several changes have been proposed. According to that, serotype A would be classified as a separate variety, C. neoformans, var. grubii. In AIDS patients, the vast majority of isolates are serotype $\mathrm{A}^{3}$ Cryptococcus neoformans serotype $\mathrm{D}$ has been more commonly isolated from these skin lesions, which could be related to dermotropism. ${ }^{4}$

The source of human infection is mainly represented by pigeon excreta, but the other bird droppings, soil and fruits may also harbor the yeast, which is usually acquired through inhalation. In immunocompetent hosts the infection is usually limited to the lungs, with minimal or no symptoms. Although cryptococcosis has been encountered most commonly in the HIV-infected population, ${ }^{5}$ a multicentre study reporting 306 cases of cryptococcosis in patients who are not infected with HIV found $0.7 \%$ of total cases occurred in human stem cell transplant (HSCT) recipients, $18 \%$ in solid organ transplant recipient, $9 \%$ in patients with hematologic malignancies, and $9 \%$ in patients with other malignancies. ${ }^{6}$ Cryptococcosis represented $3 \%$ to $8 \%$ of the invasive fungal infections in solid organ transplant (SOT) recipients with an overall mortality of $42 \% .^{2}$ In SOT patients cryptococcosis manifests as a late occurring infection with most cases occuring more than 6 months post transplant; the median time to onset was 16 to 21 months after transplantation. ${ }^{7}$ In transplant recipients, the reduction of immune defences, induced by drugs, may lead to extra pulmonary haematogenous dissemination of cryptococci, with the involvement of other organs, usually the central nervous system (CNS), as well as the skin, urinary tract, bones and joints. Overall, $61 \%$ of the SOT recipients in one report had disseminated disease, $54 \%$ had pulmonary and $8.1 \%$ had skin, soft-tissue or osteoarticular cryptococcosis. ${ }^{8}$ Cutaneous lesions may be the only sign of serious systemic disease in post-transplant immunosuppressed patients. While cutaneous lesions largely represent hematogenous dissemination, skin has also been identified as a portal of entry of cryptococcus and potential source of subsequent disseminated disease in SOT recipients.

Patients receiving a calcineurin-inhibitor-based regimen are less likely to have disseminated disease and more likely to have cryptococcosis limited to the lungs and skin as calcineurin-inhibitors also inhibits fungal calcineurin. ${ }^{9}$ Furthermore, tacrolimus suppresses the growth of $\mathrm{C}$ neoformans at $37^{\circ} \mathrm{C}$ but not at $24^{\circ} \mathrm{C}$, which suggests that the target of tacrolimus, calcineurin, is required at higher body temperatures. Thus, temperature-dependent inhibition of cryptococci by tacrolimus may prevent CNS infection but allows growth of fungus at cooler body sites, e.g., skin, soft tissue, and bone. ${ }^{10}$
Cutaneous cryptococcosis can present with papular, nodular, necrotizing fasciitis, cryptococcomas, cellulitis, palpable purpura or ulcerative lesions or rarely as panniculitis. Only 14 cases of cryptococcal panniculitis in solid organ transplant recipient have been reported till now. ${ }^{11}$ After reviewing all cases of cryptococcal panniculitis in SOT patients, we found that the duration between transplant and infection ranged from 3 months to 31 years with a mean period of 9.64 years. Age of onset of infection varied from 33-61 years and the mean age of onset was 49.64 years. Cerebreo-spinal fluid involvement was present in 5 patients, absent in 7 and was not described in 2 patients. Pulmonary involvement was present in 6 patients and was not described in 7 patients (Table 1).

The diagnosis of cutaneous cryptoccosis requires histopathology and tissue culture of a skin biopsy specimen. On histopathology, the organism can typically be visualized as an oval, thick-walled encapsulated spherule. Special staining with methylene blue, Alcian blue, or mucicarmine may be performed to demonstrate the capsule. Two patterns of involvement can be seen. ${ }^{23}$ The first is the gelatinous type, which shows numerous budding yeasts in a foamy stroma with little or no inflammation. The second is the granulomatous type, which shows fewer, smaller organisms and a granulomatous inflammatory infiltrate. This can be further confirmed by tissue culture in which the colony appears moist, shiny, and white on sabouraud dextrose agar, but it may darken with aging. In immunocompromised patients, to rule out systemic involvement a complete evaluation including collection of large volume CSF ( $\geq 1 \mathrm{ml}$ or 20 drops), blood and urine analysis should be performed. Positive serum cryptococcal antigen has been reported in $88-91 \%$ of the SOT recipients with cryptococcal meningitis. ${ }^{24}$ However, the serum and CSF antigen titers are generally lower in nonHIV infected hosts, including SOT recipients than in HIVinfected patients with CNS cryptococcosis. Patients who do not have AIDS but have single, localized skin lesions are often antigen negative.

In immunocompetent patients, disseminated, non-CNS Cryptococcus infection can be treated with oral fluconazole for 3-6 months or with itraconazole for 6-12 months. CNS involvement is treated with intravenous amphotericin B combined with flucytosine, followed by oral fluconazole. In immunosuppressed patients, the initial treatments are similar, but lifelong maintenance treatment with fluconazole may be required. Primary cutaneous disease can be treated with oral fluconazole or itraconazole. ${ }^{25}$

\section{Conclusion}

The present case highlights a rare manifestation of Cryptococcus in an immunocompromised host. Dermatologists and general physicians should be aware about varied presentations of opportunistic pathogens like cryptocossus in immunocompromised patients, which needs to be differentiated from other conditions that require different approach of management. 
Table 1. Review of case reports of cryptococcal panniculitis in solid organ transplant patients.

\begin{tabular}{|c|c|c|c|c|c|c|}
\hline Case & Age/gender & Transplant & $\begin{array}{c}\text { Interval } \\
\text { between } \\
\text { transplant and } \\
\text { infection in } \\
\text { years }\end{array}$ & Site of cutaneous lesion & $\begin{array}{l}\text { Cerebro-spinal } \\
\text { fluid } \\
\text { involvment }\end{array}$ & $\begin{array}{l}\text { Pulmonary } \\
\text { involvment }\end{array}$ \\
\hline Abuav R et al. ${ }^{12}$ & $48 \mathrm{M}$ & Heart & 11 & $\begin{array}{l}\text { Medial thigh, right foot } \\
\text { \& left flank }\end{array}$ & + & $?$ \\
\hline \multirow[t]{2}{*}{ Anderson DJ et al. ${ }^{13}$} & $52 \mathrm{M}$ & Kidney & 5 & Left leg stump & - & $?$ \\
\hline & $55 \mathrm{M}$ & Kidney & 8 & Right forearm \& leg & - & $?$ \\
\hline Bhowmik D et al. ${ }^{14}$ & $33 \mathrm{M}$ & Kidney & 13 & Left thigh & - & + \\
\hline Pasqualotto AC et al. ${ }^{15}$ & $54 \mathrm{M}$ & Kidney & 3 & Left leg cellulitis & - & - \\
\hline Orsini J et al. ${ }^{16}$ & $46 M$ & Kidney & 6 & From left thigh to ankle & $?$ & $?$ \\
\hline Gloster HM Jr et al. ${ }^{17}$ & $45 \mathrm{M}$ & Kidney & 9 & $\begin{array}{l}\text { Right thigh, left arm, right } \\
\text { arm \& left forearm }\end{array}$ & + & + \\
\hline Vo-Cong MT et al. ${ }^{18}$ & $57 \mathrm{M}$ & Kidney, liver & $\begin{array}{l}31 \text { from kidney, } \\
1 / 3 \text { from liver }\end{array}$ & Thighs \& ankles & + & $?$ \\
\hline Shrader SK et al. ${ }^{19}$ & $57 \mathrm{M}$ & Kidney & $5 / 6$ & Right medial thigh & - & + \\
\hline \multirow[t]{2}{*}{ Carlson et al. ${ }^{20}$} & $41 \mathrm{M}$ & Kidney & 8 & Left calf & + & + \\
\hline & $57 \mathrm{M}$ & Kidney & 10 & Medial left calf & $?$ & $?$ \\
\hline Baer S et al. ${ }^{21}$ & $61 \mathrm{M}$ & Kidney & 11 & Lateral right lower leg & - & $?$ \\
\hline Grossman ME et al. ${ }^{22}$ & $45 \mathrm{M}$ & Kidney & $1 / 3$ & Thighs & - & + \\
\hline Bobby Y. Reddy ${ }^{11}$ & $44 \mathrm{M}$ & Lung & 14 & Thighs \& buttocks & + & + \\
\hline Present case & $40 \mathrm{M}$ & Kidney & 7 & Thigh & - & - \\
\hline
\end{tabular}

\section{References}

1. Joshi S, Wattal C, Duggal L, Sharma A, Oberoi JK, Prasad KJ. Cutaneous cryptococcosis. J Assoc Physicians India. 2004; 52: 242-243. PMID: 15636317.

2. Wu G, Vilchez RA, Eidelman B, Fung J, Kormos R, Kusne S. Cryptococcal meningitis: an analysis among 5521 consecutive organ transplant recipients. Transpl Infect Dis. 2002; 4: 183188. PMID: 12535260.

3. Lacaz Cda S, Heins-Vaccari EM, Hernandez-Arriagada GL, Martins EL, Prearo CA, Corim SM, Martins Mdos A. Primary cutaneous cryptococcosis due to Cryptococcus neoformans var. gattii serotype $\mathrm{B}$, in an immunocompetent patient. Rev Inst Med Trop Sao Paulo. 2002; 44: 225-228. PMID: 12219115.

4. Martinez LR, Garcia-Rivera J, Casadevall A. Cryptococcus neoformans var.neoformans (serotype D) strains are more susceptible to heat than C. neoformans var. grubii (serotype A) strains. J Clin Microbiol. 2001; 39: 3365-3367. PMID: 11526180.
5. Mirza SA, Phelan M, Rimland D, Graviss E, Hamill R, Brandt ME, Gardner T, Sattah M, de Leon GP, Baughman W, Hajjeh RA. The changing epidemiology of cryptococcosis: an update from population-based active surveillance in 2 large metropolitan areas, 1992-2000. Clin Infect Dis. 2003; 36: 789-794. PMID: 12627365.

6. Pappas PG, Perfect JR, Cloud GA, Larsen RA, Pankey GA, Lancaster DJ, Henderson H, Kauffman CA, Haas DW, Saccente M, Hamill RJ, Holloway MS, Warren RM, Dismukes WE. Cryptococcosis in human immunodeficiency virus-negative patients in the era of effective azole therapy. Clin Infect Dis. 2001; 33: 690-699. PMID: 11477526.

7. Husain S, Wagener MM, Singh N. Cryptococcus neoformans infection in organ transplant recipients: variables influencing clinical characteristics and outcome. Emerg Infect Dis. 2001; 7: 375-381. PMID: 11384512. 
8. Singh N, Alexander BD, Lortholary O, Dromer F, Gupta KL, John GT, del Busto R, Klintmalm GB, Somani J, Lyon GM, Pursell K, Stosor V, Munoz P, Limaye AP, Kalil AC, Pruett TL, Garcia-Diaz J, Humar A, Houston S, House AA, Wray D, Orloff S, Dowdy LA, Fisher RA, Heitman J, Wagener MM, Husain S; Cryptococcal Collaborative Transplant Study Group. Cryptococcus neoformans in organ transplant recipients: impact of calcineurin-inhibitor agents on mortality. J Infect Dis. 2007; 195: 756-764. PMID: 17262720.

9. Neuville S, Dromer F, Morin O, Dupont B, Ronin O, Lortholary O. French Cryptococcosis Study Group. Primary cutaneous cryptococcosis: a distinct clinical entity. Clin Infect Dis. 2003; 36: 337-347. PMID: 12539076.

10. Cruz MC, Del Poeta M, Wang P, Wenger R, Zenke G, Quesniaux VF, Movva NR, Perfect JR, Cardenas ME, Heitman J. Immunosuppressive and nonimmunosuppressive cyclosporine analogs are toxic to the opportunistic fungal pathogen Cryptococcus neoformans via cyclophilin-dependent inhibition of calcineurin. Antimicrob Agents Chemother. 2000; 44: 143-149. PMID: 10602736.

11. Reddy BY, Shaigany S, Schulman L, Grossman ME. Resident Rounds Part III: Case Report: Fatal Cryptococcal Panniculitis in a Lung Transplant Recipient. J Drugs Dermatol. 2015; 14: 519-523. PMID: 25942673.

12. Abuav R, McGirt LY, Kazin RA. Cryptococcal panniculitis in an immunocompromised patient: a case report and review of the literature. Cutis. 2010; 85: 303-306. PMID: 20666191.

13. Anderson DJ, Schmidt C, Goodman J, Pomeroy C. Cryptococcal disease presenting as cellulitis. Clin Infect Dis. 1992; 14: 666-672. PMID: 1562658.

14. Bhowmik D, Dinda AK, Xess I, Sethuraman G, Mahajan S, Gupta S, Agarwal SK, Guleria S, Tiwari SC. Fungal panniculitis in renal transplant recipients. Transpl Infect Dis. 2008; 10: 286289. PMID: 18086276.

15. Pasqualotto AC, Bittar AE, de Quadros M, Severo LC. Cryptococcal cellulitis in a renal transplant patient. Nephrol Dial Transplant. 2005; 20: 2007-2008. PMID: 15814538.
16. Orsini J, Nowakowski J, Delaney V, Sakoulas G, Wormser GP. Cryptococcal infection presenting as cellulitis in a renal transplant recipient. Transpl Infect Dis. 2009; 11: 68-71. PMID: 19000155.

17. Gloster HM Jr, Swerlick RA, Solomon AR. Cryptococcal cellulitis in a diabetic, kidney transplant patient. J Am Acad Dermatol. 1994; 30: 1025-1026. PMID: 8188868.

18. Vo-Cong MT, Persu A, Marot L, Goffin E. The transplanted patient who suffered from excruciating lower limb pain and developed nodular skin lesions. Nephrol Dial Transplant. 1999; 14: 2947-2949. PMID: 10570104.

19. Shrader SK, Watts JC, Dancik JA, Band JD. Disseminated cryptococcosis presenting as cellulitis with necrotizing vasculitis. J Clin Microbiol. 1986; 24: 860-862. PMID: 3533989.

20. Carlson KC, Mehlmauer M, Evans S, Chandrasoma P. Cryptococcal cellulitis in renal transplant recipients. J Am Acad Dermatol. 1987; 17: 469-472. PMID: 3308982.

21. Baer S, Baddley JW, Gnann JW, Pappas PG. Cryptococcal disease presenting as necrotizing cellulitis in transplant recipients. Transpl Infect Dis. 2009; 11: 353-358. PMID: 19422669.

22. Grossman ME, Fox LP, Kovarik C, Rosenbach M. Cutaneous manifestations of infection in the immunocompromised host. In: Cryptococcosis. 2nd ed. New York: Springer; 2012: 23-26.

23. Guarner J, Brandt ME. Histopathologic diagnosis of fungal infections in the 21st century. Clin Microbiol Rev. 2011; 24: 247280. PMID: 21482725.

24. Singh N, Dromer F, Perfect JR, Lortholary O. Cryptococcosis in solid organ transplant recipients: current state of the science. Clin Infect Dis. 2008; 47: 1321-1327. PMID: 18840080.

25. Saag MS, Graybill RJ, Larsen RA, Pappas PG, Perfect JR, Powderly WG, Sobel JD, Dismukes WE. Practice guidelines for the management of cryptococcal disease. Infectious Diseases Society of America. Clin Infect Dis. 2000; 30: 710718. PMID: 10770733. 